\title{
Research
}

\section{Functional Amnesia: Clinical Description and Neuropsychological Profile of 10 Cases}

\author{
Mark Kritchevsky, ${ }^{1,4,6}$ Judy Chang, ${ }^{5}$ and Larry R. Squire ${ }^{1,2,3,4}$ \\ ${ }^{1}$ Department of Neurosciences, ${ }^{2}$ Department of Psychology, and ${ }^{3}$ Department of Psychiatry, University of California, San Diego, \\ La Jolla, California 92093, USA; ${ }^{4}$ VA San Diego Healthcare System, San Diego, California 92161, USA; ${ }^{5}$ Stanford Sleep Disorders \\ Clinic, Stanford, California 94305, USA
}

\begin{abstract}
We carried out the first neuropsychological study of a series of patients with functional amnesia. We evaluated 10 patients, first with a neurological examination and then with three tests of anterograde amnesia and four tests of retrograde amnesia. Excluding one patient who later admitted to malingering, all patients had a significant premorbid psychiatric history and one or more possible precipitating factors for their amnesia. Eight of the 10 patients still had persistent retrograde amnesia at our last contact with them (median $=14$ mo after the onset of amnesia). On tests of anterograde amnesia, the patients performed normally as a group, though some patients scored poorly on tests of verbal memory. On tests of retrograde amnesia, all patients had difficulty recollecting well-formed autobiographical memories of specific events from their past. In contrast, patients performed as well as controls at distinguishing the names of cities from fictitious city names. On remote memory tests for past public events and famous faces, different patients exhibited different but internally consistent patterns of impaired and spared performance. The variability in the clinical and neuropsychological findings among our patients may be understood by supposing that memory performance is poor in proportion to how directly a test appears to assess a patient's commonsense concept of memory. The presentation of patients with functional amnesia is as variable as humankind's concept of what memory is and how it works.
\end{abstract}

Bilateral damage to the medial temporal lobe or medial diencephalon is associated with a syndrome of amnesia that has been widely studied (Scoville and Milner 1957; Squire 1992; ZolaMorgan and Squire 1993). The memory impairment is characterized by intact immediate memory, marked anterograde amnesia (i.e., impaired new learning), and variable, usually temporally graded retrograde amnesia (i.e., loss of premorbid memory affecting recent memory more than remote memory). In addition, the amnesia is selective in the sense that it affects the capacity for conscious recollection of facts and events (termed declarative memory) but spares nondeclarative forms of memory that are expressed through performance, such as skills, habits, simple forms of conditioning, and the phenomenon of priming. This form of memory impairment is encountered in patients with stroke, traumatic brain injury, anoxia-ischemia, encephalitis, Korsakoff's syndrome, and most commonly, early Alzheimer's disease (Baddeley et al. 2002). Although memory impairment is often permanent, some forms, such as transient global amnesia, do resolve spontaneously (Kritchevsky et al. 1988).

In contrast to the memory impairment in these cases, which is due to neurological lesions, there is a less common condition in which patients develop severe retrograde amnesia in the absence of significant anterograde amnesia and without any known brain injury or disease. This non-neurological syndrome of memory impairment has been variously termed "hysterical amnesia," "psychogenic amnesia," or "dissociative amnesia" (American Psychiatric Association 1994), and we refer to it here as functional amnesia. Functional amnesia is the memory disorder that is most often popularized in literature and film, and it appears to be the condition that lay persons typically regard as "amnesia."

\section{${ }^{6}$ Corresponding author.}

E-MAIL mkritchevsky@ucsd.edu; FAX (858) 552-7513.

Article and publication are at http://www.learnmem.org/cgi/doi/10.1101/ Im.71404.
In early descriptions of functional amnesia based on large numbers of cases (Abeles and Schilder 1935; Kanzer 1939; Wilson et al. 1950; Kennedy and Neville 1957), the typical patient had a sudden onset of amnesia in which the main symptom was considered to be loss of personal identity. In these early reports, memory functions were not evaluated systematically, but loss of knowledge about facts and personal events was sometimes noted, and memory was reported to be generally good for events occurring after the onset of amnesia (Abeles and Schilder 1935). Recovery from this condition was considered to have occurred in almost all the cases within one month. Uncommonly, cases were reported in which functional amnesia lasted longer (case \#1 of Pratt 1977; Akhtar et al. 1981).

In 1982, the first case of functional amnesia was reported where extensive neuropsychological testing was carried out during amnesia (Schacter et al. 1982). In the years since, a number of other single-case studies have been reported that include neuropsychological findings from formal tests. In general, the findings from these case studies are in accord with the earlier clinical reports: sudden onset of retrograde amnesia, including a loss of personal identity, in the absence of significant anterograde amnesia.

Nevertheless, the findings from these newer cases raise two puzzling issues. First, in contrast to what was reported in the early clinical studies, many of the patients who were studied with neuropsychological testing did not recover from their condition, even after one or two years (e.g., Campodonico and Rediess 1996; Markowitsch et al. 1997). Second, the findings across patients were variable. Variability was apparent in the early clinical case reports and was particularly evident in the single cases studied with neuropsychological tests. Patients differed with respect to the severity of retrograde amnesia, the extent to which the amnesia affected general knowledge in addition to personal memories, and the extent to which the impairment extended beyond memory to include such things as knowledge of vocabulary, the 
names and functions of objects, and the ability to perform previously familiar skills. However, each of these single-case studies employed its own collection of neuropsychological tests and asked its own questions. Thus, it is difficult to compare the patients, and it is difficult to generalize across the studies. If common tests had been used, perhaps the variability among the patients would have been less striking.

We have carried out the first neuropsychological study of a series of patients with functional amnesia. We evaluated 10 patients, first with a neurological examination and then with formal tests: three tests of anterograde amnesia and four tests of retrograde amnesia. Patients were also given a personality inventory. In addition, insofar as was possible, we followed the patients to determine when and if recovery from amnesia occurred. One of the 10 patients confessed to malingering his amnesia, and his test scores are presented here so that they can be compared to the scores of the other patients. Preliminary findings for these patients appeared in an earlier report, which compared functional amnesia with transient global amnesia (Kritchevsky et al. 1997).

\section{RESULTS}

\section{Clinical Findings}

As a group, the patients had little or no anterograde amnesia and marked retrograde amnesia. With respect to anterograde amnesia, all of the patients had good memory for events that occurred after the onset of amnesia. One patient (SF) did complain of difficulty with new learning and, in neurological examination, was poor at learning verbal (but not nonverbal) material. However, like the other patients, he did not appear to be forgetful and gave no sign of difficulty with attention or language. With respect to retrograde amnesia, nine of the patients had loss of past memories that extended into childhood (all but DS, whose retrograde amnesia was limited to $2-3$ yrs). Seven of these nine patients did not know their name at the onset of amnesia (this information was unavailable for the remaining two). Some patients were aware of a few vague and incomplete memories within their period of retrograde amnesia. Before they were found amnesic in San Diego, California, two of the patients had periods of sudden and unexpected travel during which they apparently had exhibited normal behavior. SP traveled from another state to San Diego during a period of $2 \mathrm{~d}$. JG traveled from a southern state to San Diego during a period of $11 \mathrm{~d}$.

Nine of the patients (all but RW, who malingered his amnesia) had significant premorbid psychiatric histories that included one or more of the following: alcohol and/or other substance abuse (six patients), previous conversion symptoms (two patients), and diagnoses of anxiety disorder (one patient), posttraumatic stress disorder (one patient), chronic paranoid schizophrenia or psychosis due to longstanding alcohol and other substance abuse (one patient), depression and/or history of suicide attempt (four patients), and histrionic or borderline personality disorder (one patient). For these same nine patients, one or more possible precipitating factors could be identified, including intoxication with alcohol (three patients), mild closed head injury (two patients), active depression (five patients), witnessing a physical assault that was similar to previous repeated assaults committed against her (one patient), and involvement or alleged involvement in illegal activity (four patients). The tenth patient (RW) hit himself on the head to simulate a precipitating factor.

Eight of the patients (all but JG and DS) had one or more abnormalities, in addition to their amnesia, that were thought to be psychogenic. These included an inability to voluntarily move the eyes in formal testing, bilateral leg weakness with inability to walk independently, left-sided weakness that began shortly after the onset of amnesia, as well as anomia, inability to name numbers, difficulty with calculations, loss of ability to read and write, and loss of ability to carry out previously familiar activities (e.g., using a telephone, driving a car with manual transmission, or operating a motorcycle). One patient reported that he had to relearn the English language during the first $2 \mathrm{~d}$ of his amnesia by reading the dictionary. Another reported that she could no longer remember the Spanish language, though she had been raised in a bilingual home.

Only two patients (MD and RW, the malingerer) fully recovered from their condition. The extensive retrograde amnesia of another patient (JG) shrunk during a 6-mo period to involve only the 8 mo before the onset of amnesia. The eight patients who did not recover had significant and persistent retrograde amnesia at our last contact with them (range $=9 \mathrm{~d}$ to $42 \mathrm{mo}$, median $=14$ mo after the onset of amnesia). Two of these patients had established new personalities at the onset of amnesia, which persisted through our last contact with them at $23 \mathrm{mo}$ and $42 \mathrm{mo}$, respectively, after the onset of amnesia.

\section{Neuropsychological Findings}

\section{Tests of Anterograde Amnesia}

Figure $1 \mathrm{~A}$ shows performance on the test of story recall. The patients were marginally impaired at immediate recall $(t$ $[13]=2.1, P<.06)$, and similar overall to controls at delayed recall $(P>0.10)$. Nevertheless, the patients exhibited considerable variability in their scores, and six of the 10 patients $(M D, R W, J M$, $\mathrm{SF}, \mathrm{DS}, \mathrm{CB})$ had immediate recall scores that were more than two standard deviations below the control mean. Except for RW, all the patients obtained scores for delayed recall that were within two standard deviations of the control mean.

Figure $1 \mathrm{~B}$ shows performance on the test of paired-associate learning. A two-way analysis of variance $(2$ groups $\times 3$ learning trials) indicated that the patients and the controls performed similarly overall $(\mathrm{F}[1,13]=2.7, P>0.10)$ and improved at a similar rate across the three trials (interaction of group $X$ trials $F$ $[2,26]=0.5, P>0.10)$. Nevertheless, the patients exhibited some variability in their scores, and for four of them (MD, RW, SF, DG) the total number of words recalled across the three tests was more than two standard deviations below the overall control mean.

Figure 1C shows performance on the diagram recall test. The patients scored similarly to the controls, both when they copied the figure and when they reconstructed it from memory $(P s>0.10)$.

\section{Tests of Retrograde Amnesia}

Figure 2 shows results for the cities tests. Overall, the patients performed similarly to the controls (U.S. cities; $t[12]=1.8$, $P=.09$; California cities, $P>0.10$ ). Nonetheless, two patients (JG, JM) scored more than two standard deviations below the control mean on both tests. Notably, one of these (JM) scored only $47 \%$ correct on the U.S. cities test and 30\% correct on the California cities test (chance $=50 \%$ for each test).

Figure 3 shows performance on the test of past autobiographical memory. Patient DS, whose retrograde amnesia was limited to the 2-3 yrs before the onset of amnesia, was not given this test. The patients performed markedly poorer than the controls, both when they were scored on the basis of their unaided recollections (no probe; $t[12]=3.2, P<0.01$ ) and when they were scored on the basis of what they could recollect after encouragement from the examiner (probe; $t[12]=2.7, P<0.05$ ). Of note, the two patients who obtained the best scores (CB, DG) were tested longer after the onset of their amnesia ( 3 and $9 \mathrm{mo}$ ) than the other patients $(1 \mathrm{~d}$ to $10 \mathrm{wks}$, median $=7 \mathrm{~d})$. The good performance of these two patients resulted from the fact that

\section{Learning \& Memory}



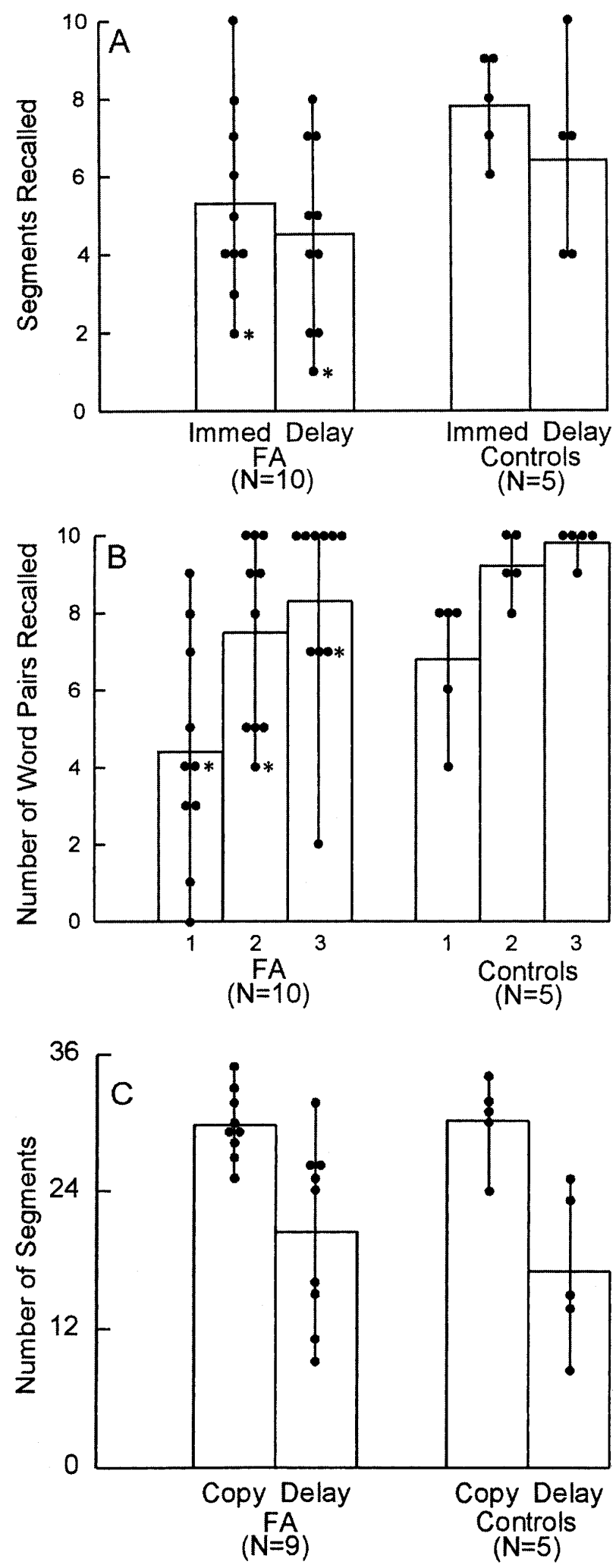

Figure 1 Performance of patients with functional amnesia (FA) and controls on tests of anterograde amnesia. $(A)$ Story recall. Recall was tested immediately (Immed) and again after a delay of 10-20 min (Delay). (B) Paired-associate learning. Ten word pairs were presented on each of three study trials. (C) Copy of a complex figure and reconstruction from memory after 10-20 min (Delay). Maximum score $=36$. Patient RW did not receive the diagram recall test. (๑) indicate the scores for each participant. *indicates scores for patient RW. they were able to draw memories from the period after the onset of their amnesia. In neurological examination, both these patients exhibited significant loss of premorbid autobiographical memories.

Figure 4 shows the percentage of well formed, 3-point episodic memories that were recalled from different past time periods ( $0 \mathrm{~d}$ to $>20 \mathrm{yrs}$ ). One patient (RW, the malingerer) was unable to produce any well formed recollections and was not included in this analysis. The remaining patients each recalled from three to 10 memories. The patients differed markedly from the controls in that they recalled most of their memories $(78 \%)$ from the most recent time period (controls $=24 \% ; t[11]=3.1, P<.01)$ and very few of their memories from the most remote time period (patients, $3 \%$; controls, $36 \% ; t[11]=3.2, P<.01$ ). All of the memories recalled by the patients from the most recent time period were drawn from the time after the onset of amnesia. Thus, compared with the controls, the patients had a striking tendency not to recall remote memories, but rather to draw their memories from the period after the onset of their amnesia.

Figure $5 \mathrm{~A}, \mathrm{~B}$ shows performance on the public events test. The four patients who took this test (EC, DS, CB, DG) were impaired both at recall (16.7\% correct for patients; $39.2 \%$ correct for controls; $t[7]=4.2, P<.01)$ and at recognition $(44.8 \%$ correct for patients; $76.6 \%$ correct for controls; $t[7]=4.2, P<.01)$. Patient DS, whose retrograde amnesia was limited to events that occurred 2-3 yrs before the onset of his amnesia, performed better than the other patients. However, he still performed at the low end of the control range on recall (29.2\%) and poorer than the controls on recognition (62.5\%). Six other patients took a similar test involving 17-26 questions about the two most recent decades and also scored poorly at recall and at recognition $(16.3 \%$ correct for recall; $48.3 \%$ correct for recognition; MD did not take the recall test). One of these five patients (JM) answered none of 18 recall questions correctly and scored only $11.1 \%$ correct on the multiple-choice recognition test (chance $=25 \%$ ).

Figure 5C,D shows performance on the test of famous faces. As a group, the four patients who took this test (SF, EC, CB, DG) were impaired both at recall $(40.8 \%$ correct for patients; $64.2 \%$ correct for controls; $t[7]=5.7, P<.01)$ and at recognition $(80.2 \%$ correct for patients; $94.7 \%$ correct for controls; $t[7]=4.2$, $P<.01$ ). Six other patients took a similar test involving $20-27$ faces from the two most recent decades and also scored poorly as a group (39.1\% correct for recall; $77.8 \%$ correct for recognition; SP did not take the recognition test). However, there was marked variability in the individual scores. Thus, both the recall and recognition scores of patients RW and JG were as good as or better than the control scores (RW: $85.2 \%$ and $98.1 \%$; JG: $59.2 \%$ and $90.7 \%$ ). Also, patient DS (whose retrograde amnesia was limited to 2-3 yrs) performed just below the controls at recall $(55.0 \%)$ and obtained a perfect score at recognition (100\%). EC scored well enough on the recognition test to reach the low end of the control range. Another patient (MD) scored $0 \%$ correct at recall but scored much better at recognition (81.5\%). Lastly, patient JM performed very poorly, just as he did on the public events test. He scored $0 \%$ correct at recall and only $18.5 \%$ correct at recognition (chance $=41.7 \%$ ). His overall score on both the public events and famous faces recognition tests (7/45 items correct) was 2.75 standard deviations below the score that would have been expected from guessing.

\section{Personality Inventory}

The nine patients (all except SP) who were administered the Mini-Mult Personality Test had abnormal profiles. Overall, compared to the controls, patients obtained significantly abnormal scores on the Depression scale and the Schizophrenia scale (ts 


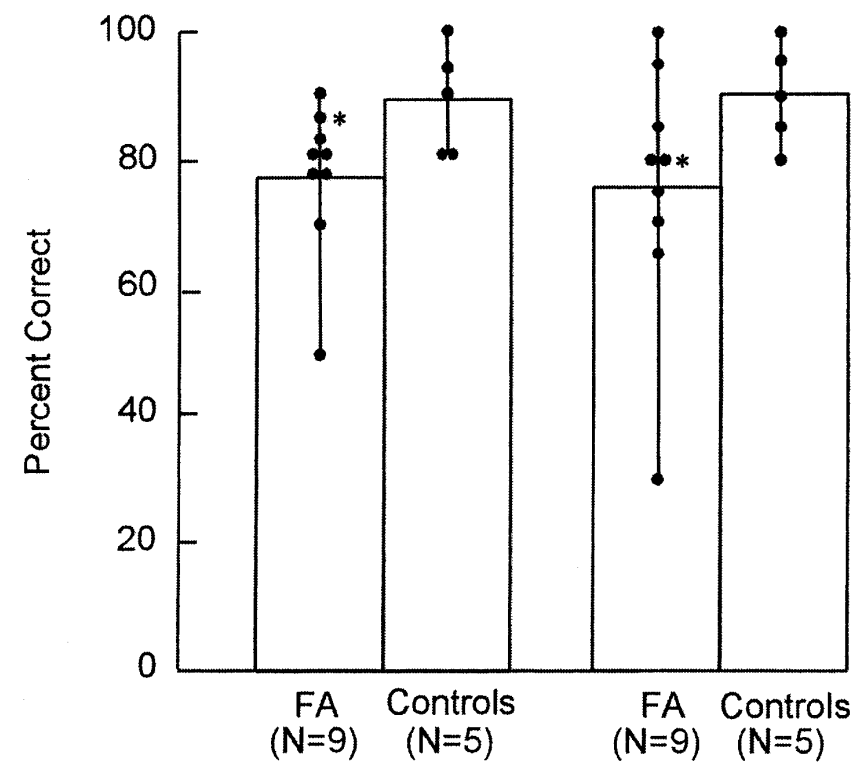

Figure 2 Patients with functional amnesia (FA) and controls were asked to identify the names of cities in the United States (left two bars) and the names of cities in Southern California (right two bars) from lists of real and fictitious city names. Patient SP was not tested. Chance $=50 \%$. $(\bullet$ Indicates the scores for each participant. $\left({ }^{*}\right)$ Indicates scores for patient RW.

$[12]>2.7, P s<.02)$. Their scores on the Hypochondriasis scale were also marginally abnormal $(t[12]=1.89, P<.09)$. Every patient had an abnormal score ( $\mathrm{T}$ score $\geq 70$ ) on at least one scale (range $=1-6$ scales). There appeared to be two patterns of scores among the patients. Three patients (RW, JM, EC) had abnormal scores on the Hypochondriasis, Depression, and Hysteria scales and not on the other scales. Five other patients (MD, JG, SF, DS, $\mathrm{CB}$ ) had especially elevated scores on the Depression and Schizophrenia scales (mean T scores $=86$ and 84, respectively). Among the other scales, three patients (MD, JG, and DS) obtained abnormal scores on the Psychopathic Deviate scale, and four patients (JG, SF, DS, CB) obtained abnormal scores on the Psychasthenia scale. One patient (DG) obtained an abnormal score only on the Schizophrenia scale.

\section{DISCUSSION}

We have carried out the first study of a series of patients with functional amnesia, all of whom received extensive neuropsychological testing during the course of their amnesic condition. Clinically, all 10 patients had severe retrograde amnesia in the absence of significant anterograde amnesia. Of the nine patients whose amnesia extended into childhood, the seven for whom information was available did not know their name at the onset of amnesia. Excluding one patient who later admitted to malingering, all patients had a significant premorbid psychiatric history and one or more possible precipitating factors for their amnesia. Eight of the 10 patients also had one or more neurological abnormalities at the onset of amnesia, in addition to memory loss, that were thought to be psychogenic. Finally, eight of the 10 patients still had significant and persistent retrograde amnesia at our last contact with them.

The patients performed well as a group on tests of anterograde amnesia for verbal and nonverbal material (Fig. 1). However, performance was somewhat variable on the verbal memory tests. Whereas all the patients scored in the control range on the diagram recall test, several patients scored more than two standard deviations below the control mean on immediate recall of the short prose passage and on the paired-associate learning test. Yet, despite poor scores on some of the tests, it is important to emphasize that none of the patients exhibited any difficulty learning and remembering day-to-day events after the onset of amnesia.

In sharp contrast to their adequate capacity for new learning, the patients had difficulty recollecting well formed autobiographical memories of specific events from their past (Fig. 3). In addition, to the extent that personal memories could be recollected, the patients differed strikingly from controls by drawing most of their memories from the period after they became amnesic (Fig. 4).

The patients as a group were also significantly impaired on remote memory tests for public events and famous faces that covered the two decades prior to the onset of amnesia (Fig. 5). Three points are of interest. First, one patient (JM) scored so poorly on the multiple-choice versions of these tests ( 7 of 45 items correct; 2.75 standard deviations below the score that would be expected by chance), that one must consider the possibility that he intentionally chose the wrong answers. Second, three patients (JG, DS, and RW, the malingerer), performed particularly well on the recall and recognition portions of the famous faces test $(66.5 \%$ correct for recall; $95.3 \%$ correct for recognition), despite performing poorly on the recall and recognition portions of the public events test $(26.4 \%$ for recall; $57.9 \%$ for recognition). Also, one patient (MD) did rather well on the famous faces recognition test $(81.5 \%$ correct) after failing altogether at recall $(0 \%$ correct). Third, in contrast to their overall poor performance on these remote memory tests, the patients as a group performed as well as controls at distinguishing the names of cities from fictitious city names (Fig. 2). Two patients (JG and JM) did score more than two standard deviations below the control mean on both tests. Nevertheless, the good performance of the group is striking, when one considers that the names of cities, like the names of famous faces and facts about public events, must be learned and stored in long-term memory.

The findings for our patients are in broad agreement with what has been reported previously in single-case studies where neuropsychological tests were given during functional amnesia.

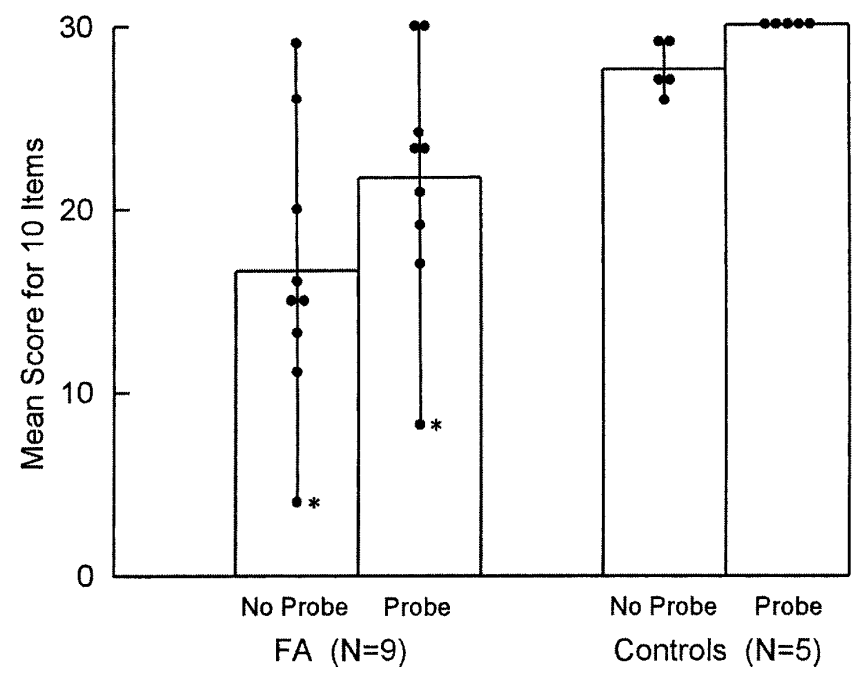

Figure 3 Patients with functional amnesia (FA) and controls were asked to recollect 10 autobiographical episodes. Responses were scored (0 to 3) before (No Probe) and after (Probe) encouragement by the examiner to elicit as specific a recollection as possible. Patient DS was not tested. (O) (O) Indicates the scores for each participant. ( $\left.{ }^{*}\right)$ Indicates scores for patient RW.

\section{Learning \& Memory




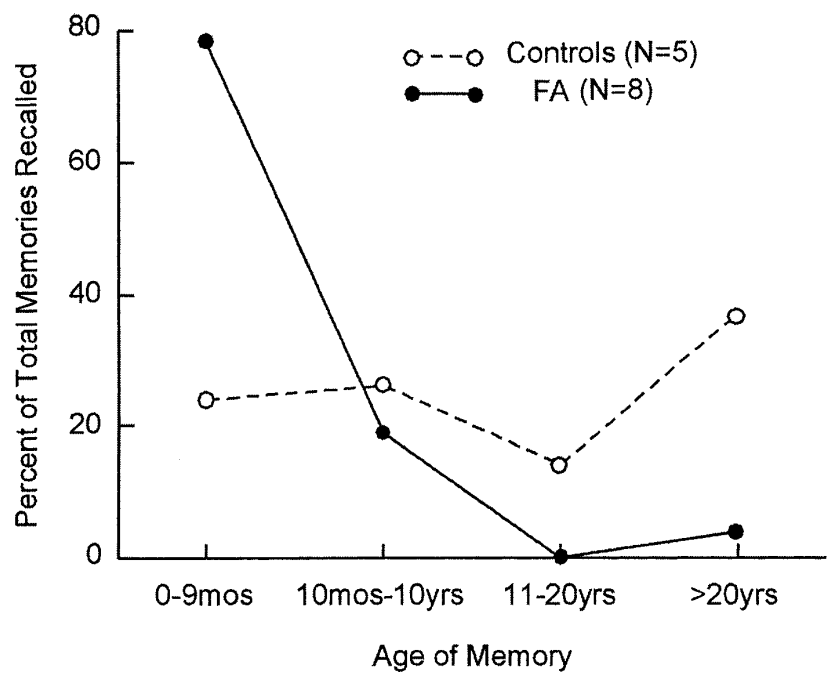

Figure 4 Percentage of memories that were recalled from the indicated time periods for patients with functional amnesia (FA) and controls. The data are based only on those recollections given a maximum score of 3 on the 10-item test of past autobiographical memory (Fig. 3). Patient DS was not tested, and patient RW had no recollections that were given a 3-point score. For the 8 patients, all the memories from the 0-9-mo time period were taken from the period after the onset of amnesia.

Specifically, one finds good anterograde memory function and significant retrograde amnesia, usually including an inability to recall one's name (see, e.g., Schacter et al. 1982; patient K of Treadway et al. 1992; Kopelman et al.1994; Barbarotto et al. 1996; Campodonico and Rediess 1996; Markowitsch et al. 1997). In other case reports, an unequivocal diagnosis was not reached, but the findings were similar to what we have described here, and we believe it likely that these other patients also had functional amnesia (e.g., De Renzi et al. 1995, 1997; patient MM of Lucchelli et al. 1995; Dalla Barba et al. 1997; Papagno 1998; MackenzieRoss 2000; Nakamura et al. 2002).

Although a typical presentation can be identified for functional amnesia (good anterograde memory, poor retrograde memory), there is considerable variability among patients, both in our own series and in the published cases. Thus, four of our 10 patients performed poorly on tests of autobiographical memory, past public events, and famous faces (for similar cases, see Campodonico and Rediess 1996; De Renzi et al. 1997; Papagno 1998). In contrast, of the nine patients given the recall and recognition famous faces test, five did well at recognizing the names of famous faces, and three of these five also did well at recalling the names (for a similar report of good performance on a famous faces test despite poor autobiographical memory, see Schacter et al. 1982; for good recognition of famous faces but poor recall of public events, see De Renzi et al. 1995). Another variation on the typical pattern is illustrated by our patient JM, who performed below chance levels on all the recognition tests (the cities tests, the public events recognition test, and the famous faces recognition test). This pattern of performance on a multiple-choice test also has been described previously (Barbarotto et al. 1996).

In most cases, memory for all or nearly all of one's personal past is initially lost. However one of our patient's retrograde amnesia, even initially, was limited to a time period of two to three years before the onset of amnesia (for another case of limited retrograde amnesia, see patient K of Treadway et al. 1992). There is also considerable variability in the extent to which memory loss extends into domains beyond autobiographical memory and fact memory. Thus, eight of our 10 patients variously exhibited anomia, difficulty in calculations, some loss of vocabulary, or inability to perform previously familiar activities. Similar descriptions are common in the published cases (De Renzi et al. 1995, 1997; patient MM of Lucchelli et al. 1995; Campodonico and Rediess 1996; Papagno 1998; Nakamura et al. 2002).

It is also worth mentioning that, even though anterograde memory function is generally intact in functional amnesia, one nevertheless finds variability among patients in this domain as well, particularly on verbal memory tests. Thus, the nine of our patients who took the diagram recall test did well at copying the figure and later reconstructing it from memory. Yet, six patients had poor immediate recall of a short prose passage (though delayed recall scores were adequate), and four had some difficulty with paired-associate learning. Among the published cases, most are reported to have fully intact anterograde memory function. Nevertheless, some patients have been reported to do poorly on immediate recall tests (Schacter et al. 1982; Barbarotto et al. 1996) or obtained poor scores on other tests of new learning (Schacter et al. 1982; De Renzi et al. 1997).

Lastly, one also finds variability with respect to recovery. Only two of our 10 patients fully recovered from their functional
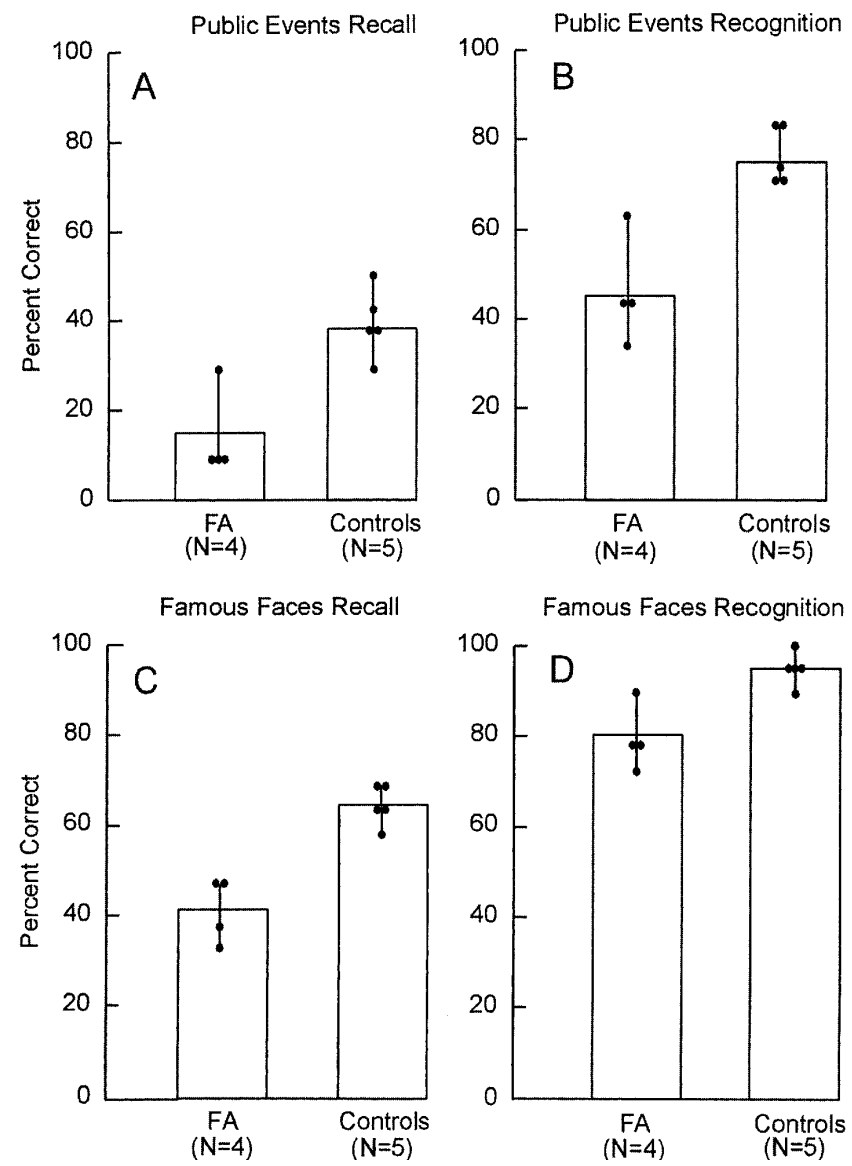

Figure 5 Performance on tests of remote memory for public events and famous faces. Participants were asked 24 questions about public events that had occurred during the two decades prior to testing $(A)$ and then took a four-alternative, multiple-choice test about the same events $(B)$. The FA data are for patients EC, DS, CB and DG. Participants also were asked to identify 19 photographs of famous people who came into the news during the two decades before testing $(C)$ and then to recognize the names that they could not recall $(D)$. The recognition score was based on the number of items recalled correctly plus the items that were recognized correctly. Chance $=41.7 \%$. The FA data are for patients SF, EC, CB and DG. (O) Indicate the scores for each participant. 
amnesia. Similarly, the majority of the patients in the published literature who have been studied with neuropsychological tests also had persistent retrograde amnesia, sometimes lasting several years (De Renzi et al. 1995, 1997; Barbarotto et al. 1996; Campodonico and Rediess 1996; Dalla Barba et al. 1997; Markowitsch et al. 1997; Mackenzie-Ross 2000; Nakamura et al. 2002). A few cases of recovery also have been reported, in these instances within 1 mo of the onset of amnesia (Schacter et al. 1982; patient MM of Lucchelli et al. 1995; Papagno 1998). It is striking that in the early clinical reports of functional amnesia, recovery from amnesia was considered to have occurred in almost all cases within 1 mo of onset (Abeles and Schilder 1935; Kanzer 1939; Wilson et al. 1950; Kennedy and Neville 1957). How can these reports be reconciled with our observation, and the observations of others, that the amnesic condition often persists? One possibility is that the early clinical studies focused on loss of personal identity as a key feature of the amnesia. Because the capacity for new learning is preserved, patients are able to learn their names after the onset of amnesia and also recover (relearn) a good deal of autobiographical and factual material that was initially inaccessible. In the absence of a careful follow-up examination, persistent gaps in memory function may be overlooked. A second possibility is that patients with retrograde amnesia lasting longer than 1 mo have sometimes not been given a diagnosis of functional amnesia and were therefore not included in the early clinical reports that described this disorder. A third possibility, perhaps less likely, is that the typical clinical course of functional amnesia has changed over the decades since the early clinical reports were published, for example, because of shifts in the culture or changes in the approach to treatment.

It is useful to contrast the condition of functional amnesia to focal retrograde amnesia, a rare neurological condition resulting most likely from bilateral damage to the anterior and inferior temporal lobes (Kapur et al. 1992; Markowitsch et al. 1993). Patients with focal retrograde amnesia typically have evidence of brain damage, minimal anterograde amnesia (which can be more severe at initial presentation), and extended retrograde amnesia for one to many decades (Kapur 1993). Loss of personal identity has not been commented upon. Previously learned skills may be spared though the patient cannot recall having learned the skill (Kapur et al. 1992). In contrast, in our cases of functional amnesia, as in previously published cases, there was no evidence of brain injury by history, neurological examination, or neuroimaging. In addition, significant anterograde amnesia was not evident at the time that neuropsychological testing revealed severe retrograde amnesia. Further, for most patients, the retrograde amnesia extended to all of the personal past and included loss of personal identity. Lastly, the presentation of retrograde amnesia was decidedly variable, with sparing of memory for famous faces in some cases, especially when testing occurred in a recognition (rather than recall) format.

The variability in the clinical and neuropsychological findings among our patients is especially helpful for reaching the conclusion that the amnesia was nonneurological, or functional, in origin. In comparison to the memory impairment in functional amnesia, the memory impairment associated with brain injury or disease presents a consistent picture. In contrast, the pattern of sparing and loss in our patients had no sound pathophysiological explanation. Even for the patients with evidence of head trauma, there was no suggestion that the injury was sufficiently severe to have caused brain damage. In addition, the presence of abnormal premorbid psychiatric histories in every patient except RW, the confessed malingerer, the evidence in many cases for psychological stress at the onset of amnesia, and the frequency of abnormalities, in addition to memory loss, that were thought to be psychogenic-all of these factors support the conclusion that the amnesia in our patients was functional and not due to a neurological lesion.

One important issue concerns the genuineness of the cases that we have reported. One patient (RW) admitted $5 \mathrm{~d}$ after the onset of his amnesia that he had malingered his condition. A second patient (JM) scored so poorly on the recognition versions of the remote memory tests (significantly below the score that could be obtained by guessing) that it is possible that he intentionally chose the incorrect answers. Is it possible that others of our patients were deliberately simulating a memory impairment? Although functional amnesia is readily distinguished from the known forms of neurological memory disorder, it is more difficult to distinguish functional amnesia with a psychogenic origin from malingering. The neuropsychological findings did not clearly discriminate between RW and the other patients, though RW did perform poorer than any of the other patients on one test of anterograde amnesia (Fig. 1A) and on one test of retrograde amnesia (Fig. 3). In fact, in the test of retrograde amnesia, he was the only patient who was unable to recall a single well formed (3-point) autobiographical memory. Lastly, RW was the only patient for whom we could not identify a significant premorbid psychiatric history.

Building on these observations, we suggest that three features of our patients' presentations favor the interpretation that they (excepting RW and possibly JM) had a genuine psychogenic or dissociative disorder that was not intentionally simulated. First, the scores on the tests that the patients performed poorly were almost never as low as they could have been. RW, the malingerer, sometimes performed worse than the others. Second, hypnosis (SP) and amytal interviews (MD, JG, and EC) improved access to past memories, and in three of these four cases access to past memories either completely recovered or continued to improve. Third, all of the patients except RW had significant premorbid psychiatric histories, including in two cases a history of conversion symptoms. Moreover, most of the patients also had significant abnormalities in addition to their memory disorder that were thought to be psychogenic. In contrast, the memory problems exhibited by RW were accompanied only by mild somatic complaints and mild difficulty with calculations.

We suggest that the striking variability in the presentation of patients with functional amnesia can be understood by supposing that performance is poor in proportion to how directly a test appears to assess a patient's commonsense concept of memory. At the heart of the condition is the severe difficulty that all patients have in recalling past personal memories. Most patients also have great difficulty remembering public events, perhaps because they are being asked to remember events that occurred in their past. In contrast to poor performance on public events tests, some patients do better at recalling the names of famous faces, and others do better still at recognizing the names of famous faces than at recalling the names, perhaps because these tests appear to assess general knowledge rather than the ability to retrieve memories. Most patients also recognize satisfactorily the names of cities, which also may be perceived as part of general knowledge. In addition, most patients do well at learning and remembering new material, perhaps because such tests appear to involve one's ability in the present moment rather than the ability to reach into the past. At the same time, for a few patients the amnesic condition is rather broad and includes loss of some vocabulary words, inability to identify common objects, as well as an inability to perform previously familiar skills. In the case of neurological amnesia, specific brain lesions are associated with consistent and specific syndromes of memory dysfunction. In the case of functional amnesia, the presentation is as variable as humankind's concept of what memory is and how it works.

\section{Learning \& Memory}




\section{MATERIALS AND METHODS}

We administered neuropsychological tests to all patients available to us $(\mathrm{n}=10)$ who met clinical criteria for functional amnesia between 1982 and 1994 . Testing occurred $1 \mathrm{~d}$ to 9 mo after the onset of their amnesia (median $=10 \mathrm{~d}$ ). The procedure was approved by the Institutional Review Boards of the UCSD School of Medicine, and the VA San Diego Healthcare System. All participants gave written informed consent to participate in the study.

\section{Subjects}

\section{Case \#1}

SP was a 46-yr-old Caucasian man who had been found by the police in an intoxicated state and brought to the Emergency Department one afternoon in 1982. In the Emergency Department, he said that he could not recall his name and that he had little recall for events that had occurred before being driven to the Emergency Department. By contacting individuals identified on business cards in the patient's wallet, it was learned that he was of Hungarian birth and had been in the United States since 1954 He had worked for at least 10 yrs as a ship's cook and had worked for approximately 6 yrs as a chef on a cruise ship. He had been diagnosed as a chronic alcoholic. He stated that he had once attempted to jump off the Golden Gate bridge to kill himself but had been stopped. Prior to his arrival in San Diego he had been living in a southwestern state for at least 8 mo. He had successfully completed a 3-wk detoxification program there, had obtained a job at a restaurant, and was living at a nearby halfway house. Three days before admission, he received his first paycheck. The following day, he told personnel at the restaurant that he had some errands to run. They had not heard from him since then.

Neurological evaluations on the date of admission revealed severe retrograde amnesia with mild and transient difficulty with calculations. Thus, he complained that he could not recall his past except that he had been a cook at some time and that he smoked cigarettes. He did not recognize his name when it was found in his wallet. He did not know his birthdate or birthplace. He did not know where he lived. He could not recall events of World War II. He was uncertain of who the president was but gave the correct name when encouraged to guess. When shown a picture of the current president standing with the two previous presidents, he was able to name all three. He was shown a handdrawn sketch of the United States and asked to place five cities. He placed Los Angeles, Miami, and Chicago correctly. He placed San Diego in west Texas. He placed Dallas at the eastern border of Texas. On initial evaluation by the Emergency Department physician, he said that 100 minus 7 was 973 and that $5 \times 5$ was 45 . On evaluation several hours later by the neurology resident, he correctly calculated 20 minus $4,14+27$, and $41 \times 3$. He appeared anxious throughout the day of admission and when asked to write a sentence he wrote, "I'm scared." Digit span was five forward and three reversed. He recalled two of three words after a 3-min delay and recognized the third word. The remainder of his neurological examination was remarkable for mild ataxia, presumably due to his alcohol use, and decreased ankle jerks presumably due to a mild alcohol-related polyneuropathy. Admission laboratory tests were remarkable for a blood alcohol level of $0.13 \mathrm{mg} /$ deciliter. CT head scan with and without contrast was normal.

During the first $5 \mathrm{~d}$ of his admission, he experienced the return of a few memories that had occurred prior to 1979. Thus, the fifth day following admission, he thought that he had spent 1959 and 1960 in Detroit, 1974 sailing in the Arctic, 1976 working on an oil tanker as a cook, and 1979 on a ship. He still could not recall his name, the names of his parents, when he had left Hungary, or whether he had a family. The following day, he was asked what he thought might have caused his memory loss. He said, "Either too much liquor, or a medical problem, or a mental stress-maybe a mental stress." He had no idea what stress might have occurred. Formal neuropsychological tests were adminis- tered on the sixth and seventh days following admission when he still had severe but not complete retrograde amnesia.

Because of persistent retrograde amnesia, a 1-h interview was performed under hypnosis following our testing on the seventh day following admission. The psychiatrist considered him to be a good hypnotic subject. During the interview, he recalled many details of his past life, including the fact that he had been in the Hungarian Air Force in 1954, that his wife and 2-yr-old daughter had accidentally drowned in 1961, and that he had recently been in a halfway house for alcohol treatment. Over the subsequent $2 \mathrm{~d}$, many additional past memories returned, including feelings of guilt and nightmares from combat in Hungary, guilt about the death of his wife and daughter, nightmares about their death, and a life of excessive alcohol use, wandering, and fearing close attachments. He described a suicide attempt by overdose in 1979. He said that his memory loss truly terrified him and that he was now motivated to obtain psychiatric help. He agreed to be transferred to the psychiatric ward for further work on regaining his memories. Later that day he disappeared unexpectedly from the hospital, did not return, and could not be found.

\section{Case \#2}

MD was a 32-yr-old Caucasian man with 9 yrs of education who was brought to the Emergency Department one morning in 1983. He complained of a generalized throbbing headache, could not recall his name or his past, and mentioned suicidal thoughts. He was intoxicated and had multiple abrasions on his head and face. Biographical information about the patient was obtained later from his father, after the patient's identity became known. The father stated that the patient had done poorly in junior high school and had dropped out during his first year of high school. His father said that the patient frequently lied, and that his biggest problem had always been that he "couldn't recall which lie he told last."

During five separate evaluations in the Emergency Department over the next $14 \mathrm{~h}, \mathrm{MD}$ presented a picture of profound retrograde amnesia with some other cognitive deficits. He told the Emergency Department physicians that his name might be Monty and that he may have fallen off a motorcycle (both of which proved to be incorrect). He said that he had a history of alcohol abuse. Ophthalmology evaluation was performed at 9:00 a.m. The patient could not recall why he had a prosthetic right eye. When visual acuity was tested using a standard test card for near vision (Rosenbaum card), the patient said that he saw the numbers but did not know their names. One hour later, the neurosurgery resident noted that the patient was unable to recall past events. The patient said incorrectly that he had not been drinking though he did report a history of alcohol abuse. He could not recall having expressed any suicidal thoughts but seemed to remember all of the other events that had occurred since he arrived at the hospital. He did not know the day, date, month, place, his last name, or how he had arrived at the hospital. He was able to recall three of three objects at $5 \mathrm{~min}$. He said that his last memory before coming to the hospital was hitchhiking near some bushes. He correctly named Reagan as the president and said incorrectly that Nixon was the president before Reagan. He could not recall any details about Nixon. When asked about the Harley Davidson motorcycle tattooed on his chest, he said that he rode a Harley Davidson motorcycle "because that's all I've ever ridden, they're the best bike there is." He could not name any other motorcycle or discuss the merits of the Harley Davidson. He could not name a pen and said that, "It's to write with." He could not name a shoe and said that, "It's to walk on." He could not name a watch. He correctly named numbers that were traced on his palms. On admission to the Neurology Service $12 \mathrm{~h}$ after his presentation to the Emergency Department, he named Reagan as president but could not name any previous president. General neurological examination was remarkable for absent ankle jerks, presumably due to a mild alcohol-related polyneuropathy. Admission laboratory tests were remarkable for a blood alcohol level of 0.26 $\mathrm{mg} /$ deciliter. CT head scan without contrast was normal.

By the following day, he was no longer intoxicated, his 
headache had resolved, and he exhibited severe retrograde amnesia with resolution of his other cognitive deficits. During the next $5 \mathrm{~d}$, formal neuropsychological testing was administered. He remained in this state for $5 \mathrm{~d}$, during which time he had occasional vague recollections about his personal past. For example, he was preoccupied one day with concerns over the whereabouts and welfare of his cousin S. He also expressed a few thoughts and opinions about his past without being able to recall any specific supportive events. Thus, he was certain that he used alcohol but not other drugs. He experienced a craving for a cigarette and thought that he probably was a smoker. During these 5 $\mathrm{d}$, his retrograde amnesia included items of general knowledge. Thus, when told four brands of motorcycles, he recognized only two (Harley Davidson and Kawasaki, but not Honda or Yamaha). He did not recognize the word Chicago, but said that Los Angeles and New York City sounded familiar. In contrast to his poor recognition of these proper nouns, he recognized several other words (walkie-talkie, volcano, Kleenex, and Scotch tape). However, he could not say what a robin was and said that the word bluejay was "associated with birds."

On the fifth day following admission, the hospital staff learned the patient's name, and this information was presented to him. This event appeared to prompt the return of many personal memories over the next $24 \mathrm{~h}$. He was able to recall his name, where he grew up, and where he lived. He recalled little of the events that had occurred during the 2 wks prior to his hospitalization, but he did recall that he had been drinking heavily for $6 \mathrm{~d}$ up to and including the day of his admission. On the seventh day following his admission, an amobarbital interview was performed and yielded good recall of all previously unremembered events, including the events of the day preceding hospitalization. He had been drinking with his cousin, $\mathrm{S}$. He recalled a fight with three unknown men. At some point he had fallen on his face, and he thought that his memory problems had probably started at that time. The day following the amobarbital interview, when his memory for the past appeared to have fully recovered, he was discharged. He agreed to come back in 2 wks for further follow-up testing but never returned.

\section{Case \#3}

RW was a 52-yr-old African-American man with 15 yrs of education who was brought to the Emergency Department one afternoon in 1985. In the Emergency Department, he complained of a painful lump on the right side of his head and stated that he could not recall what had happened to him. He was found to have severe retrograde amnesia. He stated that he knew his name only because it was on an identification card in his wallet. Additional history was subsequently obtained that shed some light on his amnesia. In 1982, he was robbed at knifepoint outside his apartment in New York City. He was brought into the bedroom and tied up while four to five people robbed him. He had felt fearful, worried, and angry since that incident. He left New York City shortly after the robbery, traveled for a year, then settled in Las Vegas for 1-1/2 yrs. Since arriving in San Diego in 1985, he had been unable to find work or an apartment that he could afford and so had lived in downtown hotels and at the downtown YMCA. He smoked marijuana 4-7 times each week but did not use alcohol or other drugs. He had presented to the Emergency Department $2 \mathrm{~d}$ previous to the present visit because of a concern about his physical health but had been reassured that he had only a musculoskeletal pain.

At the present visit, he told the Emergency Department nurse and physician that at 10:00 a.m. he had found himself sitting in a hallway at the YMCA with his toiletries next to him on the floor. He thought that he had suddenly lost consciousness and fallen to the floor and said that he might have hit his head against the wall or that someone might have hit him. He recalled walking to his room, dressing, reporting the incident to the hotel desk clerk, and being driven to the hospital. He complained of a painful lump on the back of his head on the right, an anterior chest pain that was worse when he took a deep breath, dizziness that occurred with standing and walking, possible slight weakness in his right arm and hand, and nausea. Although he would tell the neurologist who next saw him that he could not recall events that had occurred earlier in the morning, prior to his fall, he told the Emergency Department physician that he had not yet eaten that day, that he had not used drugs, and that nothing was missing from his possessions following his fall.

Neurological evaluations on the day of admission revealed severe retrograde amnesia for personal events, less severe retrograde amnesia for public events, and mild difficulties with calculation. When questioned about the past, he noted that some questions made him feel uncomfortable and that many questions evoked pictures in his mind with which he could not associate words. He could not recall his parents' names, his occupation, or how long he had been in San Diego. He thought that he might have been born in New York. (We later learned that this was correct.) He had no recall for events that had occurred prior to his fall and no recollection of the visit to the Emergency Department that he had made $2 \mathrm{~d}$ previously for evaluation of musculoskeletal pain. He correctly stated his birth year. He did not know his birth month, and when encouraged to guess, said June. (We later learned that he had been born in July.) He was uncertain of his level of education, but when encouraged he guessed that he had finished high school and college. (We later learned that he had graduated from high school and completed three years of college.) He knew that he was in San Diego, but thought he knew this because the person who had brought him to the hospital had told him. He thought that he had been staying at the downtown YMCA during his entire stay in San Diego because he could not picture anyplace else. He could not remember any of his past medical history.

He was able to correctly name the current president as Ronald Reagan, but not his political party, and noted that he had been an actor. He could not name the previous president. When asked to name any other presidents he could name only Kennedy and Roosevelt. When asked about any specific memories concerning these individuals, he recalled that he liked Kennedy. Later in the interview, he was asked whether he had any recollection of what had happened to Kennedy, and he said that he had been killed in Texas. When asked about the word Watergate, he said, "What comes to mind is a canal." When asked what countries had borders with the United States, he correctly said Canada and Mexico. When asked about Cuba, he said, "Communist country, Castro, and cigars." When asked about the World Series, he correctly noted that it was a baseball game played by the champions of the American and National Leagues. He correctly named the cities for whom the Yankees and Cubs played, but incorrectly said that the Dodgers played in Brooklyn. When asked if it were possible that the Brooklyn Dodgers had moved to Los Angeles, he said no. He correctly described a Hula-Hoop, a Frisbee, and a space shuttle. In the Emergency Department, he recalled two of three objects after a 5-min delay, and when asked to subtract serial 7s from 100 he said 100, 93, 85, 73, 62, 54 and then stated that he could not proceed further. On the neurology ward he recalled six of six words after 1-, 5-, and 10-min delays. A 2-cm tender scalp swelling was present in the occipital region. CT head scan with and without contrast was normal.

During the first $5 \mathrm{~d}$ of his hospitalization, he experienced no return of any lost memories that had occurred prior to the day of admission. Then, on the fifth day following hospital admission, he admitted that he had intentionally hit himself on the head with a bottle and faked his memory loss. He said that he had felt the need for "sanctuary" and so had sought admission to the hospital. We administered formal neuropsychological tests on the first and second days following his admission, during his malingered amnesia. Following his confession of feigned amnesia, he was transferred to the research Psychiatry Service with a diagnosis of adjustment disorder with depressed mood, and there he was treated with 8 wks of individual and group therapy. He was discharged to live in an apartment that he had rented.

\section{Case \#4}

JG was a 28-yr-old Caucasian woman with 16 yrs of education, whom we first evaluated on the Psychiatry Service in 1985. She stated that she had "psychogenic amnesia" and could not re- 
member anything from before the onset of amnesia except how to "walk and talk and play a mean game of pool." She also stated that she knew her name only because it had been told to her $2 \mathrm{~d}$ earlier. Past history was subsequently obtained from her hospital records and from her attorneys. She had obtained a Bachelor of Science degree in mathematics and subsequently served for 4 yrs in the Navy as a helicopter pilot. In 1982, during her final year in the Navy, she became depressed and suicidal following the dissolution of a previously stable, 5-yr relationship. She then, while intoxicated with alcohol, fired a pistol on the grounds of San Diego's Naval Hospital, put the gun to her head, and threatened to kill herself. She surrendered the gun to police and was hospitalized on the psychiatric unit. On the unit she was found to be dramatic, demanding, and manipulative. She had to be restrained on two occasions. Her discharge diagnosis was "histrionic personality disorder." She did well for the next year and was able to work as a computer programmer in the Southwest. In 1984, she was hospitalized on a psychiatric service for depression and a suicide attempt. She was discharged the following month with a diagnosis of borderline personality disorder. She lived with her parents in the South for the next 3 mo, then lived and worked in a nearby city for 3 mo. Subsequently, during a period of $11 \mathrm{~d}$, she drove from the southern state where she lived and worked to San Diego. She had no history of alcohol or other drug problems except for a period of excessive alcohol use in 1982.

On the day of her arrival in San Diego, in the course of being arrested for discharging her pistol on the grounds of San Diego's Naval Hospital (where she had previously discharged a firearm in 1982), she realized that she was unable to recall her past life. A forensic psychiatrist diagnosed her with malingering and she was incarcerated, but she was released after 5 wks when a polygraph test suggested that her amnesia was not malingered. She then was treated with individual psychotherapy and hypnosis with no improvement in her amnesia. Two months after her arrival in San Diego, her probation officer confronted her with her identity, which had been discovered after her gun was traced to the southern state where she had lived. She struck or attempted to strike her probation officer, said she would not go back to that state, and said she did not like her father even though she did not remember him. She refused to speak further, was brought to the Emergency Department for evaluation, and was admitted to the psychiatric service.

Neurological evaluation revealed that she had no recall for personal memories from before the onset of amnesia. After a review of hospital records indicated that she had been a Navy helicopter pilot, she was asked questions about helicopters on the following days. She was unable to answer these questions. She did not know if a checklist was used during the operation of a helicopter but did demonstrate a plausible sequence of hand and foot movements when asked to show how to fly a helicopter. The remainder of her neurological examination was normal. Formal neuropsychological tests were administered immediately following the neurological evaluation.

During the first 1-1/2 wks of her hospitalization, she had no return of old memories. She was observed to be sullen and withdrawn, and at times was manipulative, demanding, or impulsive. She sometimes expressed suicidal thoughts. During an amobarbital interview she recalled personal material up to 1-2 yrs before the interview. Thus, she discussed her family, young adulthood, and friends in the southern state where she had lived. She was able to describe extensively her helicopter training. She discussed different types of helicopters and stated that two different checklists were used in flying helicopters. Following the amobarbital interview, her severe retrograde amnesia returned and persisted through the remaining 6 wks of hospitalization. During this time her psychological status gradually improved, though on several occasions she became violent and required restraint and placement in seclusion. Finally, it was discovered that she was wanted in the southern state for a criminal offense committed on the day she began her trip to San Diego. She was discharged from the hospital. At this time she was escorted from the hospital by hospital security, turned over to San Diego police, and then extradited to her home state. It was learned later that by 6 mo follow- ing the onset of her amnesia her retrograde amnesia had shrunk and covered only the period of 8 mo before the onset of the amnesia. She subsequently pled guilty to a minor charge.

\section{Case \#5}

JM was a 37-yr-old Caucasian man whom we first evaluated in 1985. He complained of inability to recall his past and of leftsided weakness and sensory loss. He knew his name at the time we saw him, but it could not be determined whether he knew his name at the time his amnesia began, $8 \mathrm{~d}$ earlier.

Information subsequently obtained from hospital records and from his wife indicated that he was a Vietnam combat veteran and had served as a paratrooper in the Special Forces. He had $50 \%$ service-connected disability with a diagnosis of anxiety disorder. He had had many previous hospitalizations. On one occasion he had developed mild left-sided weakness following a cardiac catheterization and had been diagnosed with a stroke. On another occasion, he had been given a diagnosis of hysterical conversion reaction. He was married and had two young children. Four months before our evaluation, he and his family had moved from the Midwest to a western state. Here, he had been accused of a criminal offense.

Eight days before our evaluation, at about the time he was supposed to appear in court, he complained of a severe headache and said that he could not recognize his present surroundings or remember his past. He was taken to a local hospital, where he developed a paralysis of his left arm and leg. He was evaluated by a neurologist, who thought that his complaints were not neurological but rather due to conversion symptoms. Electroencephalogram and CT head scan were normal. He was referred for psychiatric evaluation. He was seen the following day and said that he had no independent recall for his past life previous to the onset of the headache and amnesia. He also complained of weakness on his left side. On examination, he appeared depressed, had psychomotor retardation, and spoke very softly with his head lowered. When walking he dragged his left foot and his left arm hung limply at his side. He was admitted that day for further evaluation of his retrograde amnesia and leftsided weakness.

We evaluated him with formal neuropsychological tests on the eighth and ninth days following the onset of his amnesia. He said that his left arm just hung "like dead meat," he could feel touch but not pain from a pin on the left arm, and he dragged his left leg when he walked. He complained of inability to recall any events that had occurred before the onset of amnesia. Whenever he told us something about his past, he carefully qualified it by saying, "That's what they tell me," "That's what my wife tells me," or "That's what the paper in my wallet says." His wife had told him that he rode a motorcycle. When she showed him his motorcycle, he had not recognized it. She showed him how to start it, but once the motorcycle was started he did not know how to operate it. He was impressed with the complexity of the motorcycle but was not able to recognize any of its parts or the function of these parts. When we asked him who Kennedy was, he said he did not know. When asked about the Beatles, he said that it sounded like a bug. When asked about Vietnam, he said that he had been told that there had been a war there. He added that he had never been there, though his hospital records indicated that he was a Vietnam combat veteran. He said that Scotch tape was clear tape to stick things up, Kleenex was a napkin, and a satellite was a transmitter launched into space. When asked about scissors, he said after a prolonged delay that they were "to cut paper with."

During his hospitalization, he experienced no recovery of old memories. He was discharged on the twelfth day following the onset of amnesia, for outpatient psychiatric follow-up and went to court following his discharge. At this time, when he was accused of committing the criminal offense, he said, "I don't know what they are talking about." He was found guilty and ordered to receive counseling. Our last report of him involved a hospitalization in the Midwest in 1987, for major depression. At this time, his retrograde amnesia apparently continued, as he 
claimed that he had lost most of his memories from childhood through 1985 as a result of a "stroke" that he had suffered in 1985.

\section{Case \#6}

SF was a 39-yr-old African-American man with 14 yrs of education who was admitted to the Psychiatry Service in 1992, for complaints of depression and memory loss. He had had numerous psychiatric hospitalizations in the past with conflicting diagnoses of chronic paranoid schizophrenia and organic psychosis due to longstanding alcohol and other substance abuse. Past psychotic symptoms included paranoid delusions and auditory hallucinations, including voices of FBI agents telling him to kil himself. He had intermittently complained of memory problems for 6 mo prior to the hospitalization. For example, he claimed that in 1991 he had a sudden and unwitnessed loss of consciousness. He thought that he had regained consciousness after $2 \mathrm{~min}$ and was then confused for a time. Since that episode, he had had memory problems and an abnormal tingling sensation in his extremities. He gave consistent medical histories and did not appear forgetful during examinations. However, on neurological examination he recalled only one of six objects after a 5-min delay.

Neurological evaluation 2 wks following admission indicated severe retrograde amnesia, difficulty learning and recalling new verbal material, anomia, and a "nonneurological" inability to move his eyes. He complained that he could not recall any of his past. He said that he knew his name only because it was on an identification card he had found in his wallet. He also said that he could not form new memories well, though this ability was improving. He complained of difficulties with colors and numbers, though the only example he could give was that he sometimes placed the wrong card playing solitaire because of a misperceived color or number. On examination he was alert with normal attentiveness, and he did not appear depressed. He was not forgetful during the evaluation. Nonetheless, he initially recalled none of five parts of a name and address after a 10-min delay. Given three choices, he then selected correctly each part of the name and address, except for the street number. He was able to draw from memory three of three "nonsense" figures $10 \mathrm{~min}$ after copying them with instructions to remember. He could not name the President or previous President, but correctly recognized their names when given three choices for each. He could recall none of his own past life. His language production was normal, he had no word-finding problems when speaking, and he correctly named many objects. Nevertheless, he could not name a number of common objects (watch, tie, and pen) but could describe or illustrate their use. When asked to perform saccadic or smooth pursuit eye movements, he did not move his eyes. However, throughout the examination he was observed to saccade normally in all directions, and when asked to follow his own eyes in a moving mirror, he had no difficulty with smooth pursuit. The remainder of his neurological exam was normal. Electroencephalogram was normal. Formal neuropsychological tests were administered over $2 \mathrm{~d}$, following the neurological examination.

During the week following his neurological exam, his retrograde amnesia remained severe. In contrast, his difficulties learning new verbal material and naming objects on formal testing gradually resolved. He also reported that it had taken him some time to recognize and know how to use a ping pong paddle. He was discharged from the hospital 3 wks following admission. At the last telephone follow-up with him 2 mos later, his old memories had not returned.

\section{Case \#7}

EC was a 28-yr-old Native American woman with 12 yrs of education who was admitted to the Neurology Service in 1992. She stated that she had awakened the preceding morning with no memory of her name or her past and had experienced no significant improvement in her memory since that time. Medical history obtained from her husband and review of her medical re- cords revealed that she had a history of previous alcohol and drug abuse, had been a victim of verbal, physical, and sexual abuse, and had past and ongoing conversion symptoms. For the past $15 \mathrm{mo}$, she had experienced about a dozen 30-min to 2-h long episodes of memory loss. During these periods she "forgot who her husband [and] son were, [and] what she had been doing." Twelve months previous to her admission she was evaluated for 3 mo of episodes of dimming of her vision that sometimes led to complete vision loss. No neurological cause was found for these episodes. The following month, she developed persistent weakness and sensory loss of her extremities and inability to walk. All investigations were normal and no neurological cause could be found for these complaints. She declined psychiatric evaluation.

Neurological evaluation on the day of her admission revealed that she had complete inability to recall events that had occurred prior to the previous morning, impairment of reading, writing, and calculating abilities with frequent "I don't know" and occasional "near miss" answers, and persistent sensory and motor loss in the extremities with inability to stand and walk independently. She was alert with normal attentiveness and appeared depressed. She was able to learn and recall new verbal material. In contrast, she could not recall her birthplace, her education, her previous life, knowledge of her husband from before the onset of her memory problems, her children's ages, or her previous episodes of memory loss. She said that she could no longer remember the Spanish language, though her husband had told her that she grew up speaking Spanish and English. She stated that the current year was 1990. When asked to write her first name, she wrote something that had some similarity to her name but was incorrect and was no name that we recognized in English or Spanish. When asked to write the word "dog" she wrote the letter "b," the letter "o," and then a mirror image of the letter "g." When asked to write the word "house" she wrote "hose." When asked to draw a clock, she drew a circle and placed all the numbers, but wrote the digits " 3 " and " 6 " as mirror images. There were several occasions when it appeared that she started to answer a question correctly and then suddenly stopped. She then said "I don't know" or "I don't know, but my husband could tell you." Formal neuropsychological tests were administered the day following her admission, when she still had severe and nearly complete retrograde amnesia. During this session she stated that she did not recognize her children, was surprised by how old they were, and remembered them as much younger.

During her first $4 \mathrm{~d}$ in the hospital, she experienced the return of some memories. For example, on the day following her admission, she heard people speaking Spanish in the hallway and was able to recognize and understand the words. However, she stated that she still could not speak Spanish. She told a psychiatric consultant that when she woke up the day before her admission, she thought it was 1990 and that she was living in her house by the beach. The next night, she had a dream about a man, whom her husband later identified as $S$, a former abusive boyfriend. The night following her admission, she had a nightmare about a large violent man beating a woman next to where she and her husband were sleeping. Later that evening she said, "I feel inside that what happened to the woman in my dream may have happened to me."

An amobarbital interview was conducted on the fourth day following her hospital admission. During the interview, she was asked why her memory loss had occurred. She replied that her sister-in-law had been beaten by her boyfriend while she and her children were watching. (We learned that this occurred $3 \mathrm{~d}$ before the onset of her amnesia.) During the interview, she then became distressed, cried, and said that she herself had been beaten by S. S was a brutal heroin addict who on various occasions beat her, locked her in a closet, and killed her pet animals. Following the interview, she was taken back to her room, where she became very upset and kept repeating that she wanted to help other women so that they would not have to experience what she had experienced. She was worried about her daughter and hoped that her daughter would not get involved with a man

\section{Learning \& Memory}


like S. Shortly after, she started crying and became very agitated. She was hypnotized and told to forget the content of the interview. She then slept through the night and remembered nothing of the interview the following day.

During the next month, she received psychiatric treatment for posttraumatic stress disorder, depression, conversion symptoms, and functional amnesia. She gradually recovered many past memories, including all of the memories that she had described during the amobarbital interview. As memories returned, her ability to ambulate also gradually improved. At the time of discharge she recalled many past memories, some pleasant and many unpleasant. She did not recall many other details of her past life and did not recognize some friends and family members. She walked with a cane. Six months following discharge, she stated that she could remember many events that had occurred since 1990, though she had relearned much of this information. (It was in 1990 that she had stopped seeing S, and began living with her husband and children in a stable and supportive home environment.) Her recall for events from before 1990 was very vague. Our last contact with her was 18 mo following her discharge. She still lived with her husband and children. She saw a therapist regularly. She continued to be unable to recall much of her past.

\section{Case \#8}

DS was a 54-yr old Caucasian man with $14-1 / 2$ yrs of education who came to the psychiatric emergency clinic in 1993, stating "I don't know why I am here." He could not recall how or why he had come to the hospital. He thought that it was 1991, that he lived in a trailer home with his wife, that he worked at a local toy store and that George Bush was President. A phone conversation with his "wife" revealed that they were divorced and did not live together, and that he had not worked at the toy store for 1-1/2 years. The emergency physician convinced him that he was suffering from a memory lapse, and he was admitted to the Psychiatry Service for further evaluation and treatment.

He told the admitting psychiatrist that he had come to the hospital because he "had a feeling I had an appointment" that day. (This was correct). He said that he was frightened of what could be causing his loss of memory. He reported a past history of alcohol and drug abuse but none since 1984 that he could recall. He had been married on five previous occasions and he recalled being divorced from his first four wives. Additional history was obtained from his most recent ex-wife and from his most recent girlfriend. He had been fired from his job at the toy store 16 mo before admission, after he stole $\$ 300$ to pay for work on his wife's car. He then received unemployment benefits until 3 mo before admission, when he began a sales position at a local retail business. His ex-wife had filed for divorce 9 mo before admission. About 2 mo later, he had phoned to tell her that he did not know where he was. She gave him directions to their house, and he seemed to be in a trance for $\sim 2 \mathrm{~d}$ after this. His girlfriend stated that he had written many checks for a considerable amount during the several months before his admission. Creditors had been coming by her home for about $2 \mathrm{mo}$, and she and her children were being evicted as a result of his financial indiscretions. For the several weeks before his hospital admission, he had prepared for and appeared to go to work every morning, though later information revealed that he had never arrived at work. His divorce became final $2 \mathrm{~d}$ before the hospital admission. On the morning of his hospital admission, he told his girlfriend that he was on his way to an appointment at the hospital. Hospital records revealed that he had been evaluated in the psychiatric emergency clinic $12 \mathrm{~d}$ before, and been given a diagnosis of major depression. A follow-up mental health clinic visit had been scheduled for the date on which he was admitted.

On admission, he appeared bewildered and depressed. He could not recall any personal or public events that had occurred during the last $2-3$ yrs. He had no difficulty recalling more remote events, and he formed new memories well. The remainder of his mental status examination and his general neurological examination were normal. Neuropsychological tests were administered on the thirteenth day following his admission, while he still had retrograde amnesia. At this time he stated that he could not remember events of the previous 3 yrs.

He was treated for depression and memory loss. An interview under hypnosis on the ninth day following his admission did not reveal any missing memories. Over the next several weeks he recovered some memories of the past 2-3 yrs but was uncertain whether he had recovered these memories spontaneously or simply remembered what had been told to him. His girlfriend separated from him, and he was pleased that his fifth ex-wife was willing to help him recover from his memory loss. At the time of his discharge, 1 mo after admission, he still had significant loss of memories for events that had occurred during the $2-3$ yrs prior to the onset of his amnesia. He said that he would return for clinical follow-up, but we never saw him again. Eight months later, he was admitted to a hospital in a different city with a diagnosis of bipolar affective disorder. He reported a depressed mood and suicidal ideation. On examination by the admitting psychiatrist, his recent and remote memory were found to be intact although he reported "a threeyear gap [from] 1987-1990." It was unclear to us whether the patient was now reporting memory loss for a new 3-yr period or whether the admitting physician had written down the years incorrectly.

\section{Case \#9}

CB was a 29-yr-old Native American man with 12 yrs of education whom we first evaluated in 1994 for memory loss. Three months prior to this evaluation, he had been arrested for intoxication and taken to jail. A family member brought him home from jail that night, and he went to sleep. Upon awakening the next day, he was unable to recall his past life. Medical evaluation revealed swelling of the left side of his head that was thought to be due to recent head trauma. CT head scan was normal. He was then referred for neurological evaluation. At this time he indicated that he knew his name but that for the past 3 mo he had had severe retrograde amnesia. It was not clear whether he knew his name only because he had relearned it. He also reported some difficulty recalling old vocabulary words and reported that he had forgotten how to drive a car with a manual transmission. Thus, he had essentially no memories of events that had occurred before the onset of his amnesia. He was, however, able to relearn about his past life as he was told about it. He also learned new information well. He said that with practice he had been able once again to operate a car with a manual transmission. He reported that he sometimes did not recognize vocabulary words and had to look them up.

It was notable that he described himself as having a new personality since the onset of memory problems. Previously he had been very outgoing, a heavy drinker of alcohol, and was feared by some people. He had been "obnoxious but likable." Since the onset of memory problems, he was less outgoing, more introspective, and better at getting along with other people. He did not like his personality from before the onset of memory problems, and, in fact, he had adopted his former middle name as a new first name. He hoped that he would be able to regain all of his old memories and experiences without the return of his old personality. Neurological examination revealed him to be alert and attentive. He had no recall for memories from before the onset of amnesia. The remainder of his neurological examination was normal. Formal neuropsychological tests were administered during one day in 1994.

During a 20-mo follow-up period, his severe retrograde amnesia persisted. The month after our evaluation, he spent $17 \mathrm{~d}$ in jail because of an offense that he had committed about $1 \mathrm{yr}$ before the onset of his memory problems. He read the file, could not recall any of the events, but noted that he had admitted to the offense before his memory problems began. He then pled guilty and served the jail sentence. He continued to learn about his past. He stated that he wished to continue with his new personality. An amobarbital interview was deferred because a 
treating psychiatrist did not feel that he was psychologically ready to regain his old memories.

\section{Case \#10}

DG was a 29-yr-old Caucasian man with 13 yrs of education who was first evaluated by us in 1994. He stated that he had been unable to remember most of his past life since 4 mo prior to our evaluation, when he had been involved in a motor vehicle accident. He also stated that he knew his name only because he had relearned it. History concerning his premorbid medical and psychological status was obtained from his family and from a review of his medical records. He had been an average student and a sociable, motivated, and responsible person when he entered the Army at the age of $21 \mathrm{yrs}$. At the age of 25, he was released with an honorable discharge 7 mo earlier than his family expected. His mother stated that he had not been doing his job well, and it had been suggested that he seek psychiatric help. On return from the Army, he was unmotivated and did not socialize well with his family. He was fired from jobs. He became financially irresponsible, did not pay his bills, wrote checks with insufficient funds to cover them, and was evicted on more than one occasion. One week prior to the motor vehicle accident he had been so unpleasant to his sister, with whom he had always been very close, that she told him not to visit her in the future. She stated that his condition had been worsening gradually since he came home from the Army and that he was very depressed at the time of the accident.

On the morning of the accident, he was driving without car insurance to his first day at a new telemarketing job and struck another car from behind. It was reported that he was traveling at "moderate speed," and there was "moderate damage" done to the cars. At the scene, the paramedics found him without signs of injury, but mute, combative, and uncooperative. He was taken to the Emergency Department of a nearby hospital where he appeared confused, did not respond consistently to simple yes/no questions, and would not or could not speak. Again, there were no signs of physical injury. CT head scan without contrast was normal, and he was admitted for observation. Here, a "urine" specimen that the patient provided to the nursing staff was reported by the laboratory to be apple juice. Subsequently, a physician took urine from the patient's urinal that was found to contain amphetamines. (When confronted later, the patient refused to discuss this event.) According to his family, he was unable to speak for the first $18 \mathrm{~h}$ after the accident, though six $\mathrm{h}$ after the accident he wrote "can't remember" and his name in his second language with his left hand (he was right-handed). The day after the accident he began speaking his second language. During the hospitalization, as his ability to communicate in his second language and English returned, his family realized that he had severe memory loss. He did not recognize any of his family members. He did not know his birthdate, his birthplace, his address, or where he worked. He did not know the alphabet, the months of the year, or the days of the week. He did not recognize national or religious holidays that previously had been important to him. He did not know how to use mechanical and electronic instruments such as a television remote control and a telephone. He also had difficulty with numbers and calculations. He was discharged home to his family after $1 \mathrm{wk}$.

During the next $4 \mathrm{mo}$, his family noted that he could recall some memories of events that had occurred in his childhood. Thus, he offered peanuts to his brother then quickly said, "Oh, you can't eat peanuts." In fact, his brother had been unable to eat peanuts as a child but had been able to eat them as he grew older. There also were times that he seemed to recall childhood memories as though they had just happened. When he first returned home he looked for a blue blanket that he had used as a child but not used for over 15 yrs. Although he did not recognize current pictures or voices of family members, he seemed to remember some relatives according to how they had looked or sounded 10-15 yrs before the accident. He did not appear to recall previously familiar geographical locations. Thus, when he was told that he had relatives in Arizona, he asked if he could walk from San Diego to visit them. During these 4 mo he relearned some past personal and public memories. He also enthusiastically relearned the operation of simple devices such as a telephone, a video cassette recorder, a television remote control, and household appliances. His personality also changed after the accident. He seemed more pleasant and was a more motivated student, though he was more introverted and isolated. He lost interest in his religion, which had been important to him before the accident. He was also immature and childlike in his social interactions. He was less aware of the feelings of other individuals. He did not understand jokes and interpreted them literally.

At the time of our evaluation, he told us that following the accident he had not remembered his own name or how to speak. He said that he relearned the English language during his first 2 $\mathrm{d}$ in the hospital by reading a dictionary. He had some recall for faces of persons he knew when he was very young. He had relearned other information from the past. He also complained of decreased intensity of colors perceived by the right eye, a ringing sound in the right ear, difficulty with concentration, difficulty with calculations, and mild but constant bitemporal headache, all dating to the accident. He reported that he could not work because he could not remember how to do his job and because he felt uncomfortable around strange people. He was supported by temporary disability. On examination he was unable to recall personal and public facts and events that had occurred prior to the accident. Neurological examination was otherwise normal. Brain MRI was normal 4 mo after the accident. Formal neuropsychological tests were administered 9 mo after the accident, at which time he reported no return of memories since the accident, though he had relearned many past personal and public events. Three and one-half years after the accident, his severe retrograde amnesia persisted unchanged. He had attended college successfully, though he had not finished his studies or obtained a bachelor's degree. He had difficulty keeping jobs. He continued to be socially immature and had married a woman 11 yrs older than himself who had three teenage children. They had purchased a house using his veteran's benefits. She structured his time and encouraged him to assume financial and parenting responsibilities.

\section{Procedure}

Five patients were tested between 1982 and 1985 (SP, MD, RW, JG, JM); the five others were tested between 1992 and 1995 (Table $1)$. Four men and one woman, matched to the patients with respect to age (39 yrs, range $=24-57)$ and education (15 yrs, range $=13-16)$ were recruited from volunteers and employees at the VA San Diego Healthcare System and served as controls. Their testing occurred in 1996.

\section{Tests of Anterograde Amnesia}

Anterograde amnesia was assessed with three tests: story recall, paired associate learning, and diagram recall.

\section{Story Recall}

Participants were first read a short prose passage (Gilbert et al. 1968). Recall was tested immediately and after 10 to 20 min. The score was the number of story segments correctly recalled.

Table 1. Patient Characteristics $(n=10)$

\begin{tabular}{lc}
\hline Mean age (range) & 37 yrs $(28-54)$ \\
Mean education ${ }^{\text {(range) }}$ & 13 yrs $(9-16)$ \\
Gender & 8 men, 2 women \\
Testing & 7 at $1-14$ d after onset of impairment \\
& 3 at 10 wk to 9 mo after onset \\
& (patients JG, CB, DG)
\end{tabular}

${ }^{a}$ For the eight patients for whom the level of education was known. 


\section{Paired-Associate Learning}

Participants saw 10 noun-noun word pairs on each of three study trials (Jones 1974). After each study trial, participants were shown the first word of each pair and asked to recall the second word. The score was the number of words recalled on each trial.

\section{Diagram Recall}

Participants copied either the Rey-Osterrieth (Osterrieth 1944) or Taylor (Milner and Teuber 1968) figure. After a 10-20-min delay and without forewarning, they were asked to reproduce the diagram from memory. The score was the number of parts of the figure correctly recalled.

\section{Tests of Retrograde Amnesia}

Retrograde amnesia was assessed with four tests.

\section{Cities Tests}

Each participant was read the names of 16 real and 16 plausible U.S. cities and associated states (e.g., Phoenix, Arizona, or Nelander, Michigan), as well as the names of 10 real and 10 plausible Southern California cities (e.g., Oceanside or Palmville), and asked whether each city name was real or fabricated. The score on each test was the number of cities correctly identified.

\section{Autobiographical Memory}

Ten common nouns (e.g., bird, clock, ship) were presented one at a time with the instruction to recall a specific personal event from any time in the past that involved the stimulus word (Crovitz and Schiffman 1974). Participants were asked to describe the memory in as much detail as possible and then to date the memory. When recall was not clearly specific to time and place, the examiner encouraged and suggested possible examples in order to elicit a more specific memory. Each recollection was scored on a 0 to 3 scale (maximum score $=30$ ), both before and after encouragement by the examiner (a score of 3 corresponded to a well formed, episodic memory; Zola-Morgan et al. 1983). Recollections also were scored according to the past time period from which they were drawn (Mackinnon and Squire 1989).

\section{Public Events Recall and Recognition}

The test consisted of 24 questions about public events that occurred from 1970 to 1985 , during the two decades prior to testing (Squire et al. 1989). The test was administered initially in a recall format (e.g., Who killed John Lennon?), and then in a fouralternative, multiple-choice format (John Hinkley, Sara Jane Moore, David Roth, Mark Chapman).

\section{Famous Faces Recall and Recognition}

The test consisted of 19 photographs of famous people who came into the news from 1970 to 1989 , during the two decades prior to testing (Albert et al. 1979; Squire et al. 1989). The test was administered first in a recall format in which participants were presented with each photograph and asked to name the person (e.g., Liza Minelli), and then in a recognition format. For recognition, half the items were yes/no questions (e.g., Is this person's name Liza Minelli?), and half the items were three-alternative, multiple-choice questions (e.g., Liza Minelli, Ann Margaret, Helen Reddy). The recognition score was based on the items that were recalled correctly plus the items that were recognized correctly. Chance performance was $41.7 \%$.

\section{Personality Inventory}

We also administered the Mini-Mult Personality Test (Kincannon 1968), a 71-item version of the Minnesota Multiphasic Personality Inventory (Hathaway and McKinley 1940).

\section{ACKNOWLEDGMENTS}

Supported by the Medical Research Service of the Department of Veterans Affairs, NIMH Grant 24600, and the Metropolitan Life Foundation. We thank Joyce Zouzounis and Jennifer Frascino for research assistance and Barbara Reader for manuscript preparation.

The publication costs of this article were defrayed in part by payment of page charges. This article must therefore be hereby marked "advertisement" in accordance with 18 USC section 1734 solely to indicate this fact.

\section{REFERENCES}

Abeles, M. and Schilder, P. 1935. Psychogenic loss of personal identity. Arch. Neurol. Psychiatry 34: 587-604.

Akhtar, S., Lindsey, B., and Kahn, F.L. 1981. Sudden amnesia for personal identity. $\mathrm{Pa}$. Med. 84: 46-48.

Albert, M.S., Butters, N., and Levin, J. 1979. Temporal gradients in the retrograde amnesia of patients with alcoholic Korsakoff's disease. Arch. Neurol. 36: 211-216.

American Psychiatric Association 1994. Dissociative amnesia. In Diagnostic and statistical manual of mental disorders, 4th ed., pp. 478-481. American Psychiatric Association, Washington DC.

Baddeley, A.D., Kopelman, M.D., and Wilson, B.A., eds. 2002. The handbook of memory disorders, 2nd ed. Wiley, West Sussex, UK.

Barbarotto, R., Laiacona, M., and Cocchini, G. 1996. A case of simulated, psychogenic or focal pure retrograde amnesia: Did an entire life become unconscious? Neuropsychologia 34: 575-585.

Campodonico, J.R. and Rediess, S. 1996. Dissociation of implicit and explicit knowledge in a case of psychogenic retrograde amnesia. J. Int. Neuropsychol. Soc. 2: 146-158.

Crovitz, H.F. and Schiffman, H. 1974. Frequency of episodic memories as a function of their age. Bull. Psychon. Soc. 4: 517-518.

Dalla Barba, G., Mantovan, M.C., Ferruzza, E., and Denes, G. 1997. Remembering and knowing the past: A case study of isolated retrograde amnesia. Cortex 33: 143-154.

De Renzi, E., Lucchelli, F., Muggia, S., and Spinnler, H. 1995. Persistent retrograde amnesia following a minor trauma. Cortex 31: 531-542.

De Renzi, E., Lucchelli, F., Muggia, S., and Spinnler H. 1997. Is memory loss without anatomical damage tantamount to a psychogenic deficit? The case of pure retrograde amnesia. Neuropsychologia 35: 781-794.

Gilbert, J.G., Levee, R.F., and Catalano, F.L. 1968. A preliminary report on a new memory scale. Percept. Mot. Skills 27: 277-278.

Hathaway, S.R. and McKinley, J.C. 1940. A multiphasic personality schedule (Minnesota): I. Construction of the schedule. J. Psychol. 10: $249-254$

Jones, M.K. 1974. Imagery as a mnemonic aid after left temporal lobectomy: Contrast between material-specific and generalized memory disorders. Neuropsychologia 12: 21-30.

Kanzer, M. 1939. Amnesia: A statistical study. Am. J. Psychiatry 96: 711-716.

Kapur, N. 1993. Focal retrograde amnesia in neurological disease: A critical review. Cortex 29: 217-234

Kapur, N., Ellison, D., Smith, M.P., McLellan, D.L., and Burrows, E.H. 1992. Focal retrograde amnesia following bilateral temporal lobe pathology. Brain 115: 73-85.

Kennedy, A. and Neville, J. 1957. Sudden loss of memory. Br. Med. J. 2: $428-433$.

Kincannon, J.C. 1968. Prediction of the standard MMPI scale scores from 71 items: The Mini-Mult. J. Consult. Clin. Psychol. 32: 319-325.

Kopelman, M.D., Christensen, H., Puffett, A., and Stanhope, N. 1994. The great escape: A neuropsychological study of psychogenic amnesia. Neuropsychologia 32: 675-691.

Kritchevsky, M., Squire, L.R., and Zouzounis, J.A. 1988. Transient global amnesia: Characterization of anterograde and retrograde amnesia. Neurology 38: 213-219.

Kritchevsky, M., Zouzounis, J., and Squire, L.R. 1997. Transient global amnesia and functional retrograde amnesia: Contrasting examples of episodic memory loss. Phil. Trans. R. Soc. Lond. B. 352: 1747-1754.

Lucchelli, F., Muggia, S., and Spinnler, H. 1995. The "Petites Madeleines" phenomenon in two amnesic patients: Sudden recovery of forgotten memories. Brain 118: 167-183.

Mackenzie-Ross, S. 2000. Profound retrograde amnesia following mild head injury: Organic or functional? Cortex 36: 521-537.

MacKinnon, D.F. and Squire, L.R. 1989. Autobiographical memory and amnesia. Psychobiology 17: 247-256.

Markowitsch, H.J., Calabrese, P., Haupts, M., Durwen, H.F., Liess, J., and Gehlen, W. 1993. Searching for the anatomical basis of retrograde amnesia. J. Clin. Exp. Neuropsychol. 15: 947-967.

Markowitsch, H.J., Fink, G.R., Thöne, A., Kessler, J., and Heiss, W.D. 1997. A PET study of persistent psychogenic amnesia covering the whole life span. Cog. Neuropsychiatry 2: 135-158.

Milner, B. and Teuber, H.L. 1968. Alteration of perception and memory in man: Reflections on methods. In: Analysis of behavioral change (ed. 


\section{Kritchevsky et al.}

L. Weiskrantz), pp. 268-375. Harper \& Row, New York.

Nakamura, H., Kunori, Y., Mori, K., Nakaaki, S., Yoshida, S., and Hamanaka, T. 2002. Two cases of functional focal retrograde amnesia with impairment of object use. Cortex 38: 613-622.

Osterrieth, P.A. 1944. Le test de copie d'une figure complexe. Arch. de Psychol. 30: 206-356.

Papagno, C. 1998. Transient retrograde amnesia associated with impaired naming of living categories. Cortex 34: 111-121.

Pratt, R.T.C. 1977. Psychogenic loss of memory. In Amnesia, 2nd ed., (eds. C.W.M. Whitty and O.L. Zangwill), pp. 224-232. Butterworths, London.

Schacter, D.L., Wang, P.L., Tulving, E., and Freedman, M. 1982 Functional retrograde amnesia: A quantitative case study. Neuropsychologia 20: 523-532.

Scoville, W.B. and Milner, B. 1957. Loss of recent memory after bilateral hippocampal lesions. J. Neurol. Neurosurg. Psychiatry 20: 11-21.

Squire, L.R. 1992. Memory and the hippocampus: A synthesis from findings with rats, monkeys, and humans. Psychol. Rev. 99: 195-231.
Squire, L.R., Haist, F., and Shimamura, A.P. 1989. The neurology of memory: Quantitative assessment of retrograde amnesia in two groups of amnesic patients. J. Neurosci. 9: 828-839.

Treadway, M., McCloskey, M., Gordon, B., and Cohen, N.J. 1992. Landmark life events and the organization of memory: Evidence from functional retrograde amnesia. In The handbook of emotion and memory (ed. S.Å. Christianson), pp. 389-410. Erlbaum Associates, Hillsdale, NJ.

Wilson, G., Rupp, C., and Wilson, W.W. 1950. Amnesia. Am. J. Psychiatry 106: 481-485.

Zola-Morgan, S. and Squire, L.R. 1993. Neuroanatomy of memory. Аnnu. Rev. Neurosci. 16: 547-563.

Zola-Morgan, S., Cohen, N.J., and Squire, L.R. 1983. Recall of remote episodic memory in amnesia. Neuropsychologia 21: 487-500.

Received September 30, 2003; accepted in revised form November 17, 2003. 


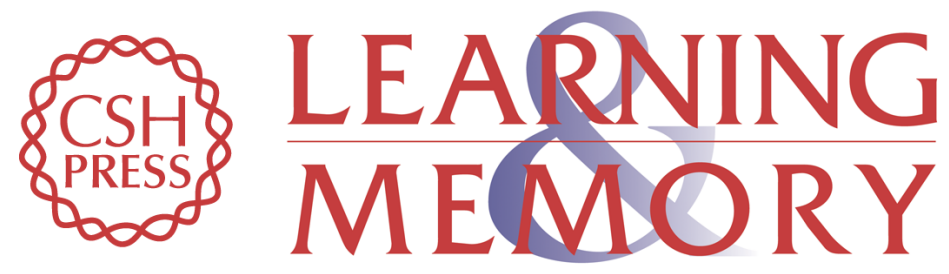

\section{Functional Amnesia: Clinical Description and Neuropsychological Profile of 10 Cases}

Mark Kritchevsky, Judy Chang and Larry R. Squire

Learn. Mem. 2004, 11:

Access the most recent version at doi:10.1101//m.71404

References This article cites 32 articles, 2 of which can be accessed free at:

http://learnmem.cshlp.org/content/11/2/213.full.html\#ref-list-1

License

Email Alerting Receive free email alerts when new articles cite this article - sign up in the box at the top Service right corner of the article or click here. 